Int. J. Electrochem. Sci., 14 (2019) 2509 - 2525

International Journal of

ELECTROCHEMICAL

SCIENCE

www.electrochemsci.org

\title{
Influences of Thermomechanical Conditions on Corrosion Behavior of low-carbon steels in Artificial Seawater
}

Dongsheng Wang ${ }^{1}$, Qianjin Zhao ${ }^{2}$, Ti Yang ${ }^{2}$, Xueting Chang ${ }^{1, *}$, Shaopeng Qu $^{1}$, Shibin Sun ${ }^{2}$, Shan Gao , Caiyi Zhang ${ }^{3}$, Xiaohui Lu $^{3}$, Yansheng Yin ${ }^{1}$

${ }^{1}$ College of Ocean science and Engineer, Shanghai Maritime University, Shanghai 200135, China

${ }^{2}$ College of logistics Engineer, Shanghai Maritime University, Shanghai 200135, China.

${ }^{3}$ Research institute of Baosteel Co., Ltd, Shanghai 201900, China.

*E-mail: xtchang@,shmtu.edu.cn

doi: $10.20964 / 2019.03 .65$

Received: 11 October 2018 / Accepted: 18 December 2018 / Published: 7 February 2019

The unprecedented global warming process causes the shrinking of sea ice in the polar region every year; hence, in order to withstand the harsh environment of this region as well as to reduce the transportation cost, a large number of high-strength steels are required to build icebreakers. The main objective of the present study was to investigate the corrosion behavior of both water-quenched and air-cooled lowcarbon steels in $3.5 \%$ artificial $\mathrm{NaCl}$ solution. It was found that after the corrosion of lamellar ferrites in pearlites and martensites, the remaining cementites aggravated the galvanic corrosion and the pitting corrosion in the matrix. Further, dislocation and the presence of large fractions of cementite in the matrix deteriorated the corrosion resistance property of the directly water-quenched sample. However, the aircooling process significantly improved the corrosion resistance behavior of the sample steel.

Keywords: Corrosion, Electrochemical impedance spectroscopy, Low-temperature carbon steel, Thermomechanical controlled process, Quenching

\section{$\underline{\text { FULL TEXT }}$}

(C) 2019 The Authors. Published by ESG (www.electrochemsci.org). This article is an open access article distributed under the terms and conditions of the Creative Commons Attribution license (http://creativecommons.org/licenses/by/4.0/). 